Article

\title{
The Pressure Peaking Phenomenon for Ignited Under-Expanded Hydrogen Jets in the Storage Enclosure: Experiments and Simulations for Release Rates of up to $11.5 \mathrm{~g} / \mathrm{s}$
}

\author{
Donatella Cirrone $^{1, *}$, Dmitriy Makarov ${ }^{1}$, Agnieszka Weronika Lach ${ }^{2} \mathbb{D}$, André Vagner Gaathaug ${ }^{2}$ \\ and Vladimir Molkov ${ }^{1}$ (D) \\ 1 HySAFER Centre, Ulster University, Newtownabbey BT37 0QB, UK; dv.makarov@ulster.ac.uk (D.M.); \\ v.molkov@ulster.ac.uk (V.M.) \\ 2 Department of Process, Energy and Environmental Technology, Faculty of Technology, Natural Science and \\ Maritime Science, University of South-Eastern Norway, 3918 Porsgrunn, Norway; \\ Agnieszka.Lach@usn.no (A.W.L.); Andre.V.Gaathaug@usn.no (A.V.G.) \\ * Correspondence: d.cirrone@ulster.ac.uk
}

check for

updates

Citation: Cirrone, D.; Makarov, D.;

Lach, A.W.; Gaathaug, A.V.; Molkov,

V. The Pressure Peaking Phenomenon

for Ignited Under-Expanded

Hydrogen Jets in the Storage

Enclosure: Experiments and

Simulations for Release Rates of up to

11.5 g/s. Energies 2022, 15, 271.

https://doi.org/10.3390/en15010271

Academic Editor: Ali Turan

Received: 30 November 2021

Accepted: 27 December 2021

Published: 31 December 2021

Publisher's Note: MDPI stays neutral with regard to jurisdictional claims in published maps and institutional affiliations.

Copyright: (C) 2021 by the authors. Licensee MDPI, Basel, Switzerland. This article is an open access article distributed under the terms and conditions of the Creative Commons Attribution (CC BY) license (https:// creativecommons.org/licenses/by/ $4.0 /)$.

\begin{abstract}
This work focuses on the experimental and numerical investigation of maximum overpressure and pressure dynamics during ignited hydrogen releases in a storage enclosure, e.g., in marine vessel or rail carriage, with limited vent size area, i.e., the pressure peaking phenomenon (PPP) revealed theoretically at Ulster University in 2010. The CFD model previously validated against small scale experiments in a $1 \mathrm{~m}^{3}$ enclosure is employed here to simulate real-scale tests performed by the University of South-Eastern Norway (USN) in a chamber with a volume of $15 \mathrm{~m}^{3}$. The numerical study compares two approaches on how to model the ignited hydrogen release conditions for under-expanded jets: (1) notional nozzle concept model with inflow boundary condition, and (2) volumetric source model in the governing conservation equations. For the test with storage pressure of $11.78 \mathrm{MPa}$, both approaches reproduce the experimental pressure dynamics and the pressure peak with a maximum $3 \%$ deviation. However, the volumetric source approach reduces significantly the computational time by approximately 3 times $(C F L=0.75)$. The sensitivity analysis is performed to study the effect of CFL number, the size of the volumetric source and number of iterations per time step. An approach based on the use of a larger size volumetric source and uniform coarser grid with a mesh size of a vent of square size is demonstrated to reduce the duration of simulations by a factor of 7.5 compared to the approach with inflow boundary at the notional nozzle exit. The volumetric source model demonstrates good engineering accuracy in predicting experimental pressure peaks with deviation from $-14 \%$ to $+11 \%$ for various release and ventilation scenarios as well as different volumetric source sizes. After validation against experiments, the CFD model is employed to investigate the effect of cryogenic temperature in the storage on the overpressure dynamics in the enclosure. For a storage pressure equal to $11.78 \mathrm{MPa}$, it is found that a decrease of storage temperature from $277 \mathrm{~K}$ to $100 \mathrm{~K}$ causes a twice larger pressure peak in the enclosure due to the pressure peaking phenomenon.
\end{abstract}

Keywords: the pressure peaking phenomenon; ignited hydrogen releases; jet fire; enclosure; cryogenic releases; experiments; CFD model

\section{Introduction}

The number of fuel cell hydrogen vehicles (FCHV) worldwide is growing and their use in day-to-day life is a reality [1]. A level of safety comparable or higher than fossil fuel vehicles should be provided for FCHV. Thus, all credible incident scenarios involving an FCHV shall be considered and analysed. The parking of a passenger car in a residential garage is a typical scenario. The majority of onboard hydrogen tanks store the gas at elevated pressures of 35-70 MPa [2]. The onboard hydrogen tanks shall be equipped 
with non-reclosing thermally-activated pressure relief devices (TPRD), as required by the regulations, e.g., Global Technical Regulation on Hydrogen and Fuel Cell Vehicles (GTR\#13) [3], to release hydrogen in the event of a fire and prevent the tank rupture with potentially catastrophic consequences. Similar scenarios include a release in hydrogen storage enclosures on board of trains, ships and planes, compressor rooms, etc.

Releases of hydrogen gas in a confined space with a limited vent size are found to produce pressure dynamics with a distinctive peak that exceeds the steady-state pressure level. This phenomenon is defined as the pressure peaking phenomenon (PPP), and can be observed for gases with density lower than air. The PPP is the most pronounced for hydrogen being the lightest gas of earth. The magnitude of the pressure peak depends mainly on the hydrogen release rate, enclosure vent size and volume. The phenomenon was first revealed and explained theoretically in [4] for unignited hydrogen releases. It was found that the produced pressure peak in an enclosure could be significantly higher than thresholds for the destruction of civil structures of the order of 10-20 kPa. That study analysed a hydrogen release with a constant flow rate through a TPRD of $5.08 \mathrm{~mm}$ diameter in a typical $30.4 \mathrm{~m}^{3}$ garage with a single vent of dimensions $10 \times 25 \mathrm{~cm}$, which is about a single brick size. Overpressure in the enclosure was simulated to increase up to $50 \mathrm{kPa}$ and $100 \mathrm{kPa}$ for 35 and $70 \mathrm{MPa}$ storage pressures, respectively. After the peak, the pressure decreased tending to a steady-state value. The same authors investigated the PPP following the blowdown of several hydrogen inventories for a variety of release diameters, enclosure vent sizes and enclosure volumes [5]. It was found that a release diameter as low as $0.55 \mathrm{~mm}$ would be required for a $5 \mathrm{~kg}$ hydrogen inventory at $35 \mathrm{MPa}$ to prevent an overpressure causing major damage and possible collapse of a civil structure with volume $30 \mathrm{~m}^{3}$ and vent size providing a ventilation rate of 0.18 air changes per hour $(\mathrm{ACH})$. Brennan and Molkov provided an engineering tool in a form of nomograms to estimate overpressure in an enclosure following a sustained unignited hydrogen release [6] The pressure peaking phenomenon is significantly more pronounced for ignited hydrogen releases, i.e., jet fires, as demonstrated in [7], thus requiring a further reduction of TPRD release area to prevent structural damage. It was shown that an unignited hydrogen release through a TPRD diameter of $2 \mathrm{~mm}$ from a $70 \mathrm{MPa}$ storage generates the PPP overpressure of $11 \mathrm{kPa}$ acceptable to prevent destruction to a garage. However, the PPP overpressure increased drastically to approximately $200 \mathrm{kPa}$, when the release from the same TPRD $=2 \mathrm{~mm}$ was ignited, resulting in structural damage. Garage vents with an area of up to 4 bricks ( $10 \times 25 \mathrm{~cm}$ each) were found to be not sufficient to prevent the structure destruction, conversely to unignited releases. The reduced model to predict the pressure peaking phenomenon dynamics for both unignited and ignited releases was proposed in [7]. The model was validated against experiments on hydrogen releases with a mass flow rate in the range $0.1-1.1 \mathrm{~g} / \mathrm{s}$ in a comparatively small enclosure with dimensions $\mathrm{H} \times \mathrm{W} \times \mathrm{L}=1.00 \times 0.98 \times 0.96 \mathrm{~m}$.

The PPP validation experiments at real scale enclosure for moderate hydrogen storage pressures in the range 2.3-12.4 MPa were performed in the HyTunnel-CS project and described in [8,9]. The PPP tests for unignited hydrogen releases with mass flow rate up to $10.1 \mathrm{~g} / \mathrm{s}$ were performed in a $2.5 \times 2.0 \times 2.98 \mathrm{~m}$ chamber of approximately $15 \mathrm{~m}^{3}$ volume [8]. The experimental work was complemented by analytical modelling to demonstrate the relationship between ventilation area, enclosure volume and release rate. The same largescale facility was employed to investigate the PPP for ignited hydrogen releases [9]. For unignited tests, as expected, the measured pressure peak was increasing with the increase of hydrogen mass flow rate, whereas it was seen to decrease for increasing ventilation area. Overall, thirty-one experiments were performed for three different vent areas and hydrogen mass flow rate up to $11.7 \mathrm{~g} / \mathrm{s}$ (three tests were used in this study with maximum flow rate of $11.5 \mathrm{~g} / \mathrm{s})$. The maximum overpressure, recorded at a sensor located on the enclosure wall at $1.49 \mathrm{~m}$ above the floor and $1.5 \mathrm{~m}$ from the jet fire axis, was approximately $48 \mathrm{kPa}$. The authors complemented their experimental work with analytical modelling showing a $\pm 2 \mathrm{kPa}$ accuracy. 
Computational fluid dynamics (CFD) is a contemporary engineering tool to simulate complex scenarios without restrictive assumptions typical for reduced models. The CFD simulations allow calculation of the thermal load on enclosure surfaces and the hazard distances based on pressure and thermal effects in the external surroundings of the enclosure. A CFD model for simulating the PPP for reacting hydrogen releases was suggested in [10]. The model was based on a RANS approach for turbulence modelling and the eddy dissipation concept (EDC) for combustion. The CFD model was validated against tests in a $1 \mathrm{~m}^{3}$ enclosure for hydrogen mass flow rates of approximately 0.55 and $1.1 \mathrm{~g} / \mathrm{s}$. Simulations employed a Courant-Friedrichs-Lewy number (CFL $=(u \cdot \Delta t) / \Delta x)$ equal to 7.5 , requiring approximately one week to calculate a $2 \mathrm{~s}$ pressure transient on a 64-core machine. The computational time would increase to over a month if a CFL $=1$ was used. It follows that if a similar CFL and space discretization $\Delta x$ were to be applied for hydrogen releases with higher inlet velocity and longer durations, the required computational time would become not viable for safety engineering assessments. It was assessed that the use of a refined mesh with $4 \times 4$ control volumes $(\mathrm{CVs})$ at the notional nozzle exit would require approximately 550 days for a CFL number of 1 . The computational study in [10] investigated the significance of different heat transfer mechanisms. The radiative heat transfer was shown to constitute a significant fraction of released energy compared to conductive heat transfer through the enclosure walls, perhaps due to a short time to achieve the PPP for the latter phenomena to make an effect on the simulated overpressures. The validated CFD model was then applied to the real-scale scenario of a garage with dimensions $4.5 \times 2.6 \times 2.6 \mathrm{~m}$ [11]. The vent size was comparatively large of $0.35 \times 0.55 \mathrm{~m}$, whereas the hydrogen release rate into the compartment was approximately $300 \mathrm{~g} / \mathrm{s}$ through a $3.34 \mathrm{~mm}$ diameter TPRD. For unignited releases, the overpressure in the enclosure did not reach harmful levels for people and structure, being below $0.6 \mathrm{kPa}$. However, the study demonstrated that other hazards arose: the garage was seen to be engulfed in a flammable atmosphere in less than $1 \mathrm{~s}$, while the oxygen depletion reached levels harmful for people. When the jet was ignited, overpressure rose to over $50 \mathrm{kPa}$, thus reaching the levels of harm for humans and damage for structures following an explosion. Beyond the enclosure vent, the harmful thermal effects for humans associated with the presence of combustion products were seen to reach a hazard distance of $9 \mathrm{~m}$. Simulations were computationally expensive, requiring over a month to calculate pressure dynamics for $1 \mathrm{~s}$ when a CFL number equal to 1 was used. This calculation time may not be viable for safety engineering assessments and, as a consequence, increase of CFL up to 10 was applied.

The present study aims to further develop and expand the validation domain of the CFD model [10] for the assessment of pressure effects due to the PPP for hydrogen jet fires in a larger scale garage-like enclosure of $15 \mathrm{~m}^{3}$ volume at moderate hydrogen storage pressures up to $12.4 \mathrm{MPa}$ and mass flow rates up to $11.5 \mathrm{~g} / \mathrm{s}$. The simulations using Ulster's CFD model are validated against experiments performed by the University of South-Eastern Norway [9]. The CFD model accounts for gases compressibility, species transport with chemical reactions, radiation heat transfer etc., and as shown in $[8,9]$ requires significant computational power and simulation time. To overcome this issue, for the first time, the CFD model of the PPP uses the volumetric source model for hydrogen release source to significantly reduce the simulation time while maintaining reasonable accuracy. Storage of hydrogen as a cryogenic fluid has the potential to become a popular solution for the $\mathrm{H}_{2}$ infrastructure, due to its gains in volumetric capacities [12]. As an example, increasing attention has been given to the use of $\mathrm{LH}_{2}$ in maritime applications to fulfil the objectives for greenhouse gases emissions reduction over the next decades. Maritime applications would require the storage of large quantities of $\mathrm{LH}_{2}$ in confined spaces. To the authors' knowledge, experimental and numerical studies on the potential of PPP for cryogenic hydrogen releases indoors are currently absent in literature. A better understanding of such phenomenon is crucial for a safer deployment of cryogenic hydrogen infrastructure. In addition to the validation and assessment of the proposed CFD approaches for hydrogen stored at ambient temperature, the present study investigates for the first time the PPP 
for cryogenic ignited hydrogen releases. Simulations employ the validated CFD model to assess the effect of storage temperature on the overpressure dynamics in the enclosure.

\section{Description of Validation Experiments}

The PPP validation experiments were performed by the University of South-Eastern Norway (USN) within the HyTunnel-CS project. Details on the experimental facility and setup are described in [9]. A total of 31 tests were conducted on ignited hydrogen releases with mass flow rate up to $11.72 \mathrm{~g} / \mathrm{s}$ in a steel chamber with inner dimensions $2.5 \times 2.0 \times 2.98 \mathrm{~m}$ and $2 \mathrm{~cm}$ wall thickness. Figure 1 a represents a scheme of the experimental facility. The chamber was equipped with three openings for venting combustion products during experiments (see V1, V2 and V3 in Figure 1a). Vents were circular with a diameter of $80 \mathrm{~mm}$ and they were fully closed or opened according to the desired vent area for each test. A further opening for air supply (V4) was equipped with a fan and was designed to ventilate the enclosure in between tests. A fifth opening (V5) was used for inserting the pipes of the fuel supply, i.e., propane for the ignition device and hydrogen for the jet fires. The hydrogen release pipe was located on a $15 \mathrm{~cm}$ height stand placed at the centre of the enclosure floor (see Figure 1c). The pipe had a $6 \mathrm{~mm}$ length above the stand and internal diameter of $4 \mathrm{~mm}$. The hydrogen was released through the pipe exit with diameter $4 \mathrm{~mm}$ into the enclosure. An automatic ball valve was used to control the hydrogen release and provide a quasi-steady-state hydrogen mass flow rate. The measurement of static pressure with a closed valve was considered as the storage pressure (see Table 1 ). The ignition device was a propane pilot flame (2.1 bar and $6 \mathrm{~mm}$ diameter pipe). Ignition had a duration of $2 \mathrm{~s}$ and was activated $1 \mathrm{~s}$ before the hydrogen release.

Measurement of pressure in the test chamber was provided by a Kulite pressure transducer located on the enclosure wall at $1.49 \mathrm{~m}$ above the floor (P1 in Figure 1). Pressure sensors were not equipped with a silicon layer to further protect readings from the effect of high temperature combustion products. The hydrogen release rate was measured by a Coriolis mass flow rate meter. One thermocouple was placed $6 \mathrm{~cm}$ off the side plate at a height of $0.035 \mathrm{~cm}$ (T1 Figure 1). A second thermocouple was located $6 \mathrm{~cm}$ of the front wall at a height of $1.24 \mathrm{~m}$ (T2 in Figure 1). Two thermocouples were placed $6 \mathrm{~cm}$ off the backplate wall at heights 1.85 and $2.85 \mathrm{~m}$ (T3 and T4 in Figure 1). All thermocouples were Type K Autek-TD20H-KP. Ambient pressure and temperature were 101,325 Pa and 277 K, respectively. The initial temperature of the enclosure was given by the average of the four thermocouples T1-T4.

Experiments were performed for mass flow rates (MFR) in the range 1.0-11.7 g/s. The number of open vents was chosen to avoid pressure levels destroying the enclosure. As a consequence, tests with high MFR were performed only for two or three open vents. The maximum pressure was reached in Test $19(48.1 \mathrm{kPa})$ with $8.62 \mathrm{~g} / \mathrm{s}$ hydrogen release and only one open vent.

Three tests with the largest storage pressure and recorded PPP overpressure, and available thermocouples measurements for each of the open vents' scenarios, i.e., 1, 2 or 3 vents open, were selected for CFD model validation in the present study. Table 1 reports the storage pressure, $P_{S}$, and hydrogen mass flow rate, $\dot{m}$, for each of the selected for the simulations tests.

Table 1. The USN experiments for the CFD model validation.

\begin{tabular}{ccccc}
\hline Test No. & $\begin{array}{c}\text { Hydrogen } \\
\text { Storage } \\
\text { Pressure, MPa }\end{array}$ & $\begin{array}{c}\text { Mass Flow Rate, } \\
\text { g/s }\end{array}$ & $\begin{array}{c}\text { Number of } \\
\text { Open Vents }\end{array}$ & $\begin{array}{c}\text { Maximum } \\
\text { Measured } \\
\text { Overpressure, kPa }\end{array}$ \\
\hline 14 & 11.78 & 11.37 & 3 & 21.1 \\
\hline 18 & 12.46 & 11.47 & 2 & 33.2 \\
\hline 19 & 8.93 & 8.62 & 1 & 48.1 \\
\hline
\end{tabular}




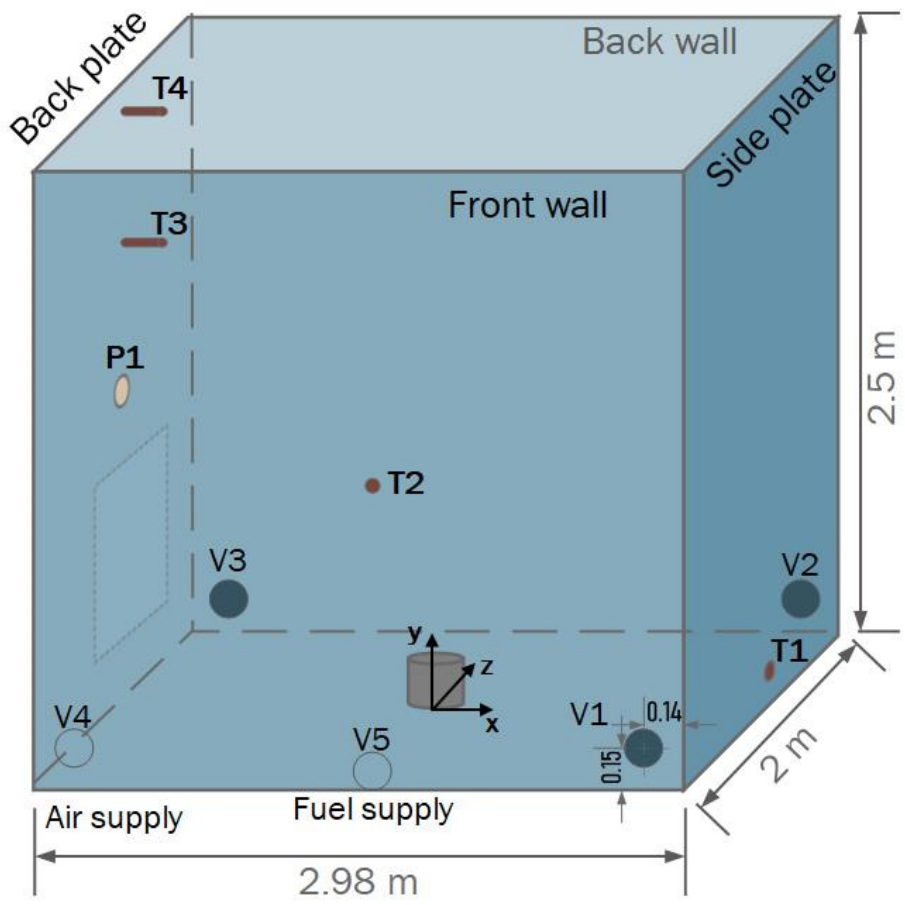

(a)

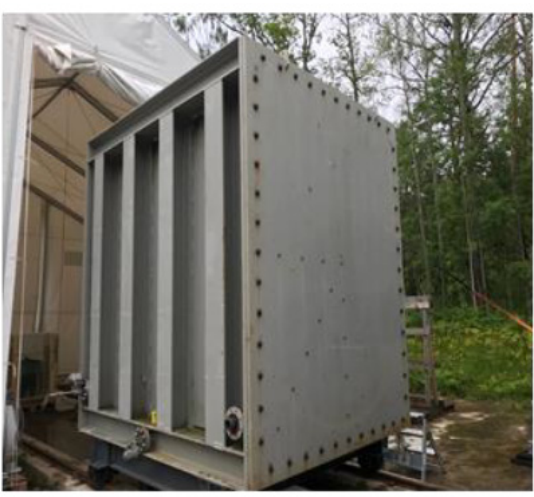

(b)

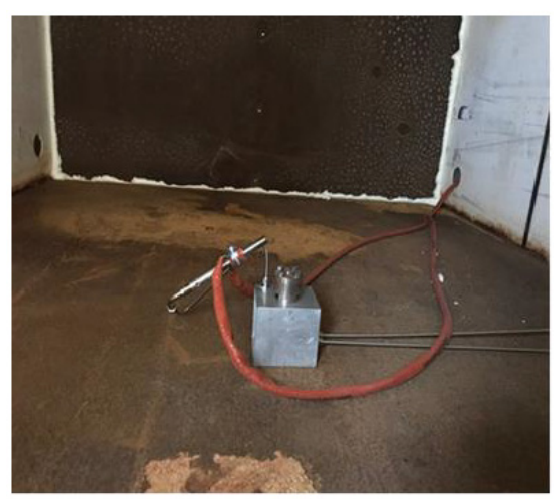

(c)

Figure 1. Experimental facility: (a)—sketch of the facility with the location of vents (V1-V3), air supply (V4), fuel supply (V5), pressure transducer (P1) and thermocouples (T1-T4); (b) - picture of the facility front wall; (c) - location of stand with hydrogen release nozzle and propane pilot flame [9].

\section{The CFD Model and Numerical Details}

\subsection{The CFD Model}

The basis of the CFD model to simulate the pressure peaking phenomenon for hydrogen jet fires in confined space was developed in [10]. The model was validated against small-scale experiments in a laboratory-scale enclosure of $1 \mathrm{~m}^{3}$ volume. Here, the model is developed further and the validation domain is expanded to the large-scale garage-like enclosure of $15 \mathrm{~m}^{3}$ volume. The CFD model employs an implicit pressure-based solver for reacting compressible ideal gas flows. A Reynolds-Averaged Navier-Stokes (RANS) approach is used with the realizable $\mathrm{K}-\varepsilon$ sub-model for solving turbulent kinetic energy and turbulence dissipation rate [13]. This turbulence sub-model is selected as it was found to better predict overpressure [10], jet fire temperature and emitted radiation [14], compared to standard $\mathrm{k}-\varepsilon$ and RNG $\mathrm{k}-\varepsilon$ models. The eddy dissipation concept (EDC) model is used for combustion simulations [15]. The option with chemical mechanisms of 9 species and 18 reactions by a subset of Peters and Rogg's mechanism [16] was applied. The discrete 
ordinates model [17] is applied to account for radiation heat transfer. The main governing equations are presented in [10], and the peculiarities of the CFD model applied in this study are described in sections below.

\subsection{Modelling of Hydrogen Release Source}

Hydrogen storage pressure in the considered experiments was in the range of 8.9312.46 MPa. Thus, the release will be in a form of an under-expanded jet, which would lead to a complicated shock waves structure outside the real nozzle.

The notional nozzle (NN) model is the first of two approaches used to model hydrogen jet in the simulations. The diameter of the notional nozzle was calculated using the Ulster's under-expanded jet theory [18], which assumes an isentropic expansion from the stagnation pressure in a storage vessel through the real nozzle and, finally, the jet expansion to the atmospheric pressure through the notional nozzle exit. This theory uses Abel-Noble Equation of State (EOS) to account for the non-ideal behaviour of hydrogen gas at high pressure. The equations for energy and mass conservation are employed in an assumption of a sonic flow to calculate conditions at the notional nozzle exit. Full description of the methodology and equations is available in [18].

The discharge coefficient, $C_{d}$, is applied in calculations of notional nozzle exit to account for pressure losses in the piping system and real nozzle compared to the ideal case of no losses with $C_{d}=1$. The discharge coefficient can be calculated through the inverse problem method targeting to match the simulated mass flow rate to the measured in an experiment, $\dot{m}_{\text {exp }}$, as follows:

$$
\dot{m}_{\text {exp }}=C_{d} \cdot \rho \cdot u \cdot A \text {. }
$$

where $\rho$ is the hydrogen density at the real nozzle, $u$ is the flow velocity (equal to the speed of sound due to choked flow conditions) and $A$ is the area of the real nozzle $\left(1.26 \times 10^{-5} \mathrm{~m}^{2}\right)$. Table 2 presents the calculated notional nozzle parameters that are used as the boundary conditions in the CFD simulations. The discharge coefficient is found to be $C_{d}=0.12-0.13$, as a consequence of the friction and minor losses in the piping system, which was approximately $2 \mathrm{~m}$ long of $4 \mathrm{~mm}$ internal diameter, with a valve, several pipe bends and the mass flow meter.

Table 2. Notional nozzle exit parameters used as hydrogen inlet boundary conditions in simulations *

\begin{tabular}{cccccc}
\hline Test No. & Mass Flow Rate, $\mathbf{g} / \mathbf{s}$ & $\boldsymbol{C}_{\boldsymbol{d}}$ & $\boldsymbol{D}_{\boldsymbol{N}}, \mathbf{m m}$ & $\boldsymbol{T}_{\boldsymbol{N}}, \mathbf{K}$ & $\boldsymbol{U}_{\boldsymbol{N}}, \mathbf{m} / \mathbf{s}$ \\
\hline 14 & 11.37 & 0.13 & 11 & 230.8 & 1154.5 \\
\hline 18 & 11.47 & 0.12 & 11 & 231.7 & 1156.6 \\
\hline 19 & 8.62 & 0.12 & 9.5 & 231.7 & 1156.6 \\
\hline${ }^{*} D_{N N}$ is the notional nozzle exit diameter, $T_{N N}$ and $U_{N N}$ are the hydrogen temperature and velocity in the
\end{tabular}
notional nozzle exit.

The second approach applied in this study is the modelling of hydrogen release using the so-called volumetric source model. The volumetric sources are applied in equations of conservation of mass, momentum and energy for a selected volume. The source terms for mass, momentum and energy are calculated from the mass flow rate, velocity and temperature at the notional nozzle reported in Table 2. This approach is proved to reduce the calculation time compared to the notional nozzle concept approach. Previous numerical work [18] demonstrated that a volumetric source with size four times the notional nozzle diameter correctly reproduced experiments on unignited hydrogen jets. The present study employs the volumetric source model applied in the space of cubic geometry with a size of $3.8 \mathrm{~cm}$, which corresponds to four times the hydraulic notional nozzle exit diameter for Test No.14. 


\subsection{Computational Domain and Numerical Grid}

The computational domain has dimensions $6.0 \times 3.5 \times 5.0 \mathrm{~m}$ and is shown in Figure $2 \mathrm{a}$. The enclosure is located at a height of $0.5 \mathrm{~m}$ from the external ground and at the centre of the domain in other directions. For the first modelling approach, the enclosure solid walls are included in the numerical domain to account for heat transfer to and through them (Figure 2a). The thickness of the rectangular control volumes (CVs) in the solid wall is $2 \mathrm{~mm}$ at the inner surface of the enclosure. This increases perpendicularly to the outer wall surface with a growth ratio of 1.1 . The inflow boundary corresponds to the notional nozzle exit and is modelled as a square with an area equivalent to that of the round notional nozzle exit. The inflow area was discretised by $2 \times 2$ cells. The cell size in the fluid was increased with a maximum cell growth ratio of 1.1. Enlargement of the numerical mesh in the near zone to the release point is shown in Figure 2c. The vents were modelled as squares with dimensions $7 \times 7 \mathrm{~cm}$, with area equivalent to the circular vents used in experiments $\left(4.9 \times 10^{-3} \mathrm{~m}^{2}\right)$. The vent area was discretised by $4 \times 1$ cells. The overall $\mathrm{CV}$ number in the domain is 575,840 . Another numerical grid was built to test simulations sensitivity for the nozzle resolution, i.e., with just $1 \times 1$ cell in the nozzle. This numerical grid presents a more refined mesh close to the enclosure walls and contains $636,666 \mathrm{CVs}$.

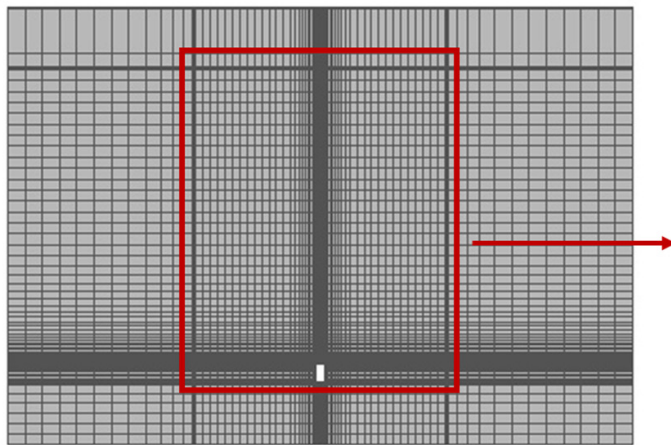

(a)

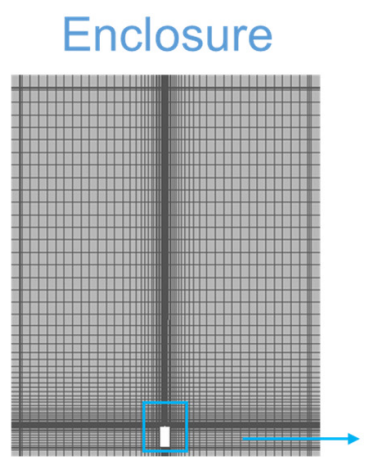

(b)

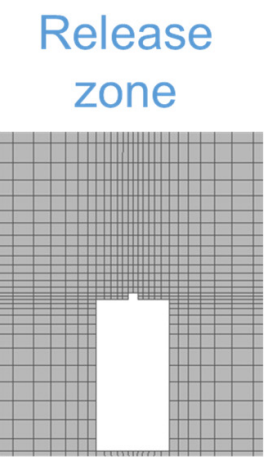

(c)

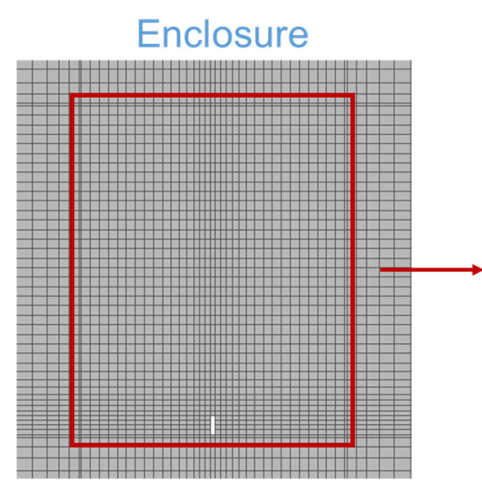

(d)

\section{Release}

zone

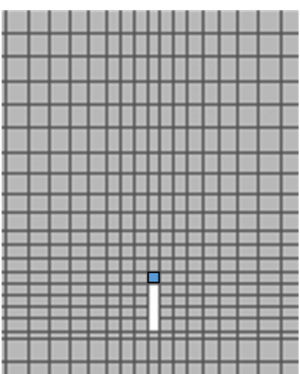

(e)

Figure 2. Cross-section of the calculation domain and numerical mesh: inflow boundary for notional nozzle exit approach-(a) total calculation domain, (b) detail of the enclosure, (c) enlargement of the release zone; volumetric source (VS) approach-(d) enclosure, (e) enlargement of the release zone with VS in light blue.

A constant mass flow rate inlet boundary condition is imposed as in the experiments. A turbulent intensity of $25 \%$ and turbulent length scale of $0.07 D_{\text {not }}$ are accepted at the inlet boundary following [14]. Properties for SAE 1010 steel are considered for the solid walls: $59 \mathrm{~W} / \mathrm{mK}$ for the thermal conductivity, $7832 \mathrm{~kg} / \mathrm{m}^{3}$ for the density and $434 \mathrm{~J} / \mathrm{kgK}$ for the specific heat [19]. The enclosure walls emissivity was taken as 0.94 [20]. The external boundaries are modelled as pressure outlets at ambient temperature and pressure, which 
are used as initial conditions in the domain, respectively 101,325 $\mathrm{Pa}$ and $277.15 \mathrm{~K}$ for Test No.14. The air composition is taken as 0.21 for the mole fraction of $\mathrm{O}_{2}$ and 0.79 for $\mathrm{N}_{2}$. The highest velocity in the domain is at the hydrogen release area, where the numerical mesh is characterised by the smallest CV size of approximately $5 \mathrm{~mm}$, thus resulting in the largest CFL number in the calculation domain. Hydrogen temperature and velocity at the release are constant in time. Therefore, in the present case, setting a constant time step during hydrogen release is equivalent to a constant CFL number. The time step is initially set as $0.34 \mathrm{~ms}$ which is equivalent to CFL number 50 at the release source. A CFL sensitivity analysis is conducted in Section 4.1 to ensure results independence from the time step (CFL number). The number of iterations per time step is set as 20. Simulations were performed using ANSYS Fluent version 16. However, no difference was observed with results obtained using Fluent version 19.2.

In the second approach for hydrogen release modelling, i.e., the volumetric source model, the numerical grid for the source area employs one cubic cell with a size of $3.8 \mathrm{~cm}$ located at the top exit of the release pipe (see Figure 2e). A growth ratio of 1.1 is maintained for the numerical grid within the enclosure. For this case, the heat transfer to and through the solid walls is modelled using a "shell conduction" approach that allows to assess the conductive heat transfer without meshing the wall thickness in the preprocessor. During the solution process, five layers of mock hexa cells are created within the steel wall, starting from a thickness of $2 \mathrm{~mm}$ at the inner wall and growing with the ratio of 1.1 in direction of the outer wall surface. The total number of control volumes in the domain was 235,881, thus reducing the $\mathrm{CV}$ number more than twice compared to that for the domain with an inflow boundary condition at the notional nozzle exit. Given the larger cell size and smaller velocity at the release source to conserve momentum and energy, a lower CFL is expected compared to the inflow boundary modelling approach for the same time step. However, the use of a coarser grid throughout the enclosure may affect CFL solution convergence. For this reason, a CFL sensitivity analysis is conducted in Section 4.2. Simulations for a volumetric source model were performed using ANSYS Fluent version 19.2.

For both modelling approaches, the discrete ordinates (DO) model was applied with discretisation $5 \times 5$ for rays and $3 \times 3$ for pixels as suggested in Fluent's best practices [21] The least-square cell-based scheme is used for the discretisation of gradients except for pressure gradients. Pressure gradients are discretised using PRESTO! scheme as it was shown to provide better predictions of experiments in [10]. A second-order upwind scheme is used to discretize the convective terms. The CFD approach employs an implicit scheme for time discretization. In the study [10], a 1st order time resolution was seen to give similar results to 2 nd order, so it is employed here to reduce computational costs. Simulations employ under-relaxation factors (URFs) of equations in the range $0.3-1.0$. These allow to control the update of the computed variables at each iteration for a pressure-based solver. The URFs are defined for each equation as follows: URF $=0.3$ for pressure, URF $=0.5$ for energy, $\mathrm{URF}=0.7$ for momentum, $\mathrm{URF}=0.75$ for density and turbulent viscosity, $\mathrm{URF}=0.8$ for the turbulent kinetic energy and dissipation rate, $\mathrm{URF}=0.85$ for the body forces, $\mathrm{URF}=0.9$ for species and, finally, $\mathrm{URF}=1.0$ for discrete ordinates. The Chemkin thermodynamic and transport databases are used to describe the species properties [22].

\section{Results and Discussion}

This section presents the discussion of the results of CFD simulations of the experimentally recorded pressure peaking phenomenon in the large-scale enclosure. The comparison of two different approaches to model the hydrogen release source is mainly focused on the pressure dynamics recorded in the enclosure, which is the primary concern of the safety analysis for such scenarios.

\subsection{Inflow Boundary at the Notional Nozzle Exit Approach}

The first analysis is focused on the reproduction of the experimental pressure dynamics within the enclosure for Test No.14 by employing the inflow boundary conditions at the 
notional nozzle exit. Figure 3 shows the comparison between experimentally recorded pressure transient and simulated pressure dynamics obtained with a different resolution of the nozzle, i.e., $1 \times 1 \mathrm{CV}$ and $2 \times 2 \mathrm{CVs}$. The simulations with a $2 \times 2 \mathrm{CVs}$ resolution at the notional nozzle exit boundary used time steps $(\Delta t) 0.17 \mathrm{~ms}$ and $0.34 \mathrm{~ms}$, which correspond to CFL numbers at the release area of approximately 25 and 50, respectively. Simulated pressure transients were shifted by $1.4 \mathrm{~ms}$, which corresponds approximately to the time needed by the mass flow rate to reach a constant value at the release nozzle in the experiments. The experimental pressure dynamics in the enclosure is well reproduced in simulations with both CFL numbers 25 and 50. The pressure in the enclosure increases as long as the volumetric flow rate of hydrogen entering the chamber is higher than the volumetric flow rate of gases leaving the chamber. The latter increases in time due to two factors: (a) the decrease of density of the gas mixture in the enclosure by the increase of hydrogen fraction, and (b) the increase of pressure in the enclosure to compensate for the growth of pressure due to hydrogen inflow by the increase of gas mixture outflow rate through the enclosure vent. The maximum pressure in the enclosure is reached when the outflow volumetric rate through the vent is equal to the volumetric flow rate of hydrogen into the chamber. Simulations well predict the experimental peak overpressure of $21.1 \mathrm{kPa}$ with an accuracy of $3 \%$ for $\Delta t=0.17 \mathrm{~ms}(20.5 \mathrm{kPa})$ and $5 \%$ for $\Delta t=0.34 \mathrm{~ms}(20.1 \mathrm{kPa})$. Given the negligible difference in the obtained pressure up to $6 \mathrm{~s}$, it is concluded that the time step equal to $0.34 \mathrm{~ms}$ can be accepted. Thus, simulation then continued only for $\Delta t=0.34 \mathrm{~ms}$, given the associated significant saving of computational time. At approximately $9 \mathrm{~s}$ the hydrogen release is stopped (see Figure 3) and maximum velocity in the calculation domain starts to decrease, allowing to gradually increase time step. The time step was doubled five times till it reached $5.4 \mathrm{~ms}$, each time letting the simulation run for 20 time steps before the next time step increase. The time step $5.4 \mathrm{~ms}$ is maintained for the rest of the simulation. Figure 3 shows that beyond $9 \mathrm{~s}$, the pressure rapidly decreases reaching negative values. Experimental negative pressure peak is seen to reach approximately $-4 \mathrm{kPa}$, whereas CFD simulation prediction is about $-2 \mathrm{kPa}$. Experimentalists noted that water vapour started condensing at the cold walls of the enclosure. Condensation could affect the pressure dynamics but was not accounted for in the model. This may be a reason for the discrepancy between the simulated and experimental negative pressure transients. Another reason could be the resolution of the vent area.

Figure 4 a shows the distribution of hydroxyl $(\mathrm{OH})$ mole fraction in the plane $x=0$ perpendicular to the enclosure walls in the location of vents. The presence of hydroxyl is an indicator of the location of chemical reactions i.e., the combustion zone in the jet fire. A limit to $\mathrm{OH}$ mole fraction equal to 0.001 is generally considered to indicate the most reacting zone and estimate a jet fire flame length [23]. The latter was seen to be consistent with the visible flame length corresponding to the region with temperature in the range 1300-1500 K [24] in the numerical study by [25]. It can be seen that the jet fire hits the enclosure ceiling. With time, the jet fire increases in width and the maximum $\mathrm{OH}$ mole fraction decreases, as an indication of a decreased reaction rate due to decreased concentration of air in the enclosure. Figure $4 \mathrm{~b}$ shows the temperature distribution in the enclosure with time. The high-temperature zone (>1800 K) impinges on the ceiling and the hot combustion products move along the ceiling and then descend along the enclosure walls. By the time $5.4 \mathrm{~s}$, the enclosure starts to be filled up with hot combustion products. This creates potentially harmful conditions for humans by temperature criteria and oxygen depletion. Similar to what observed from the $\mathrm{OH}$ mole fraction distribution, the jet fire increases in width (see zone $\mathrm{T}>1300 \mathrm{~K}$ in Figure $4 \mathrm{~b}$ ) and the maximum temperature along the jet axis decreases with time. 


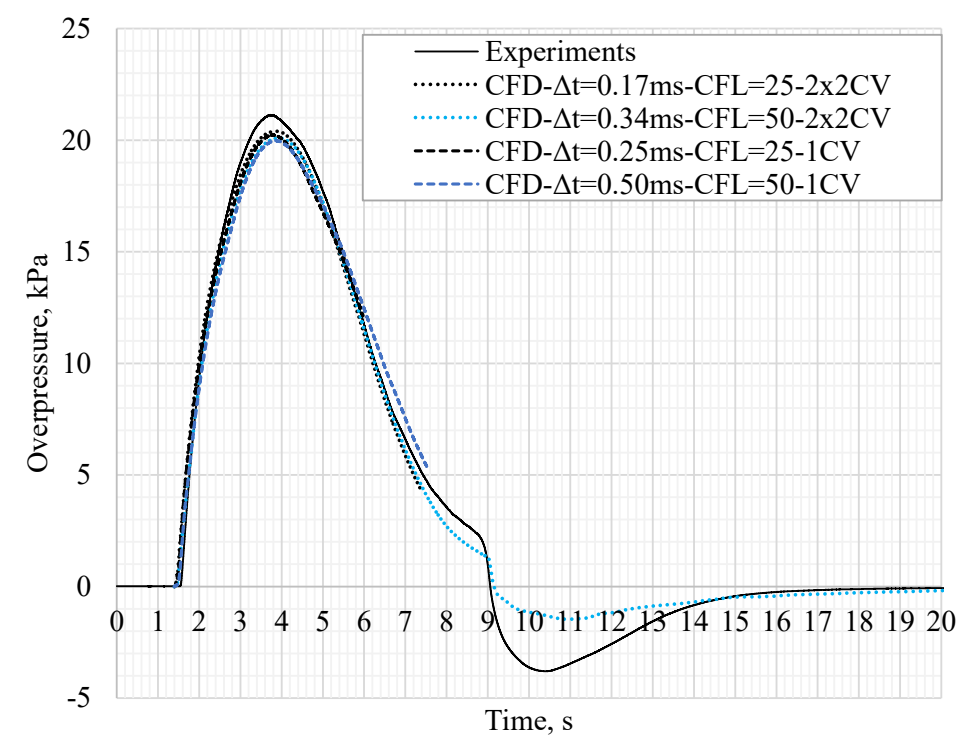

Figure 3. Simulated pressure dynamics in the enclosure with inflow boundary conditions at the notional nozzle exit for different CFL number and nozzle grid refinement (CVs) versus experimental pressure transient for Test No.14 $\left(P_{S}=11.78 \mathrm{MPa}, \dot{m}=11.37 \mathrm{~g} / \mathrm{s}\right.$, Number of simulated experimental vents $=3$ ).

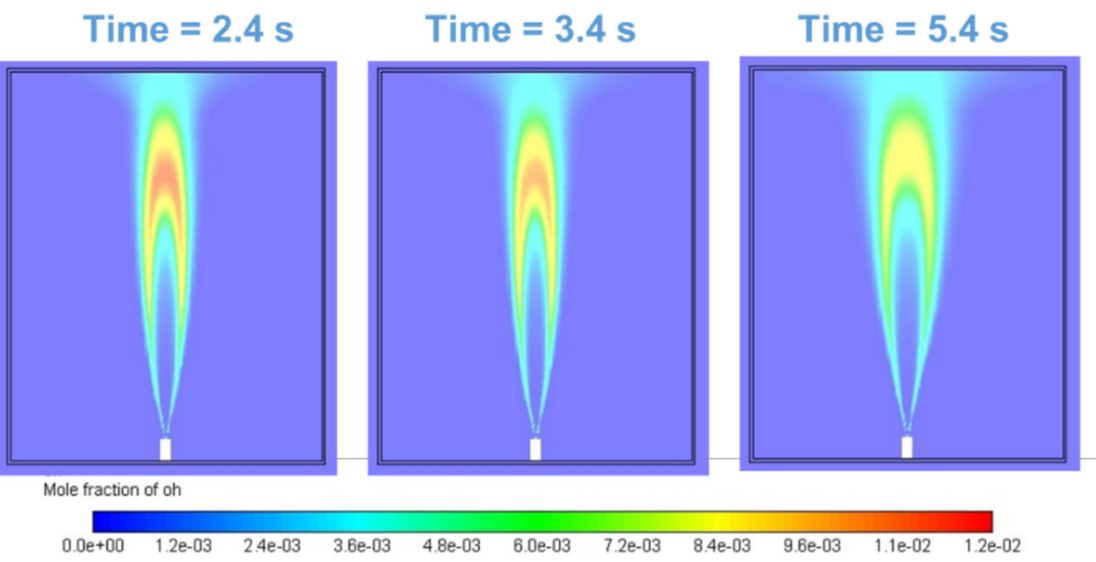

(a) $\mathrm{OH}$ mole fraction

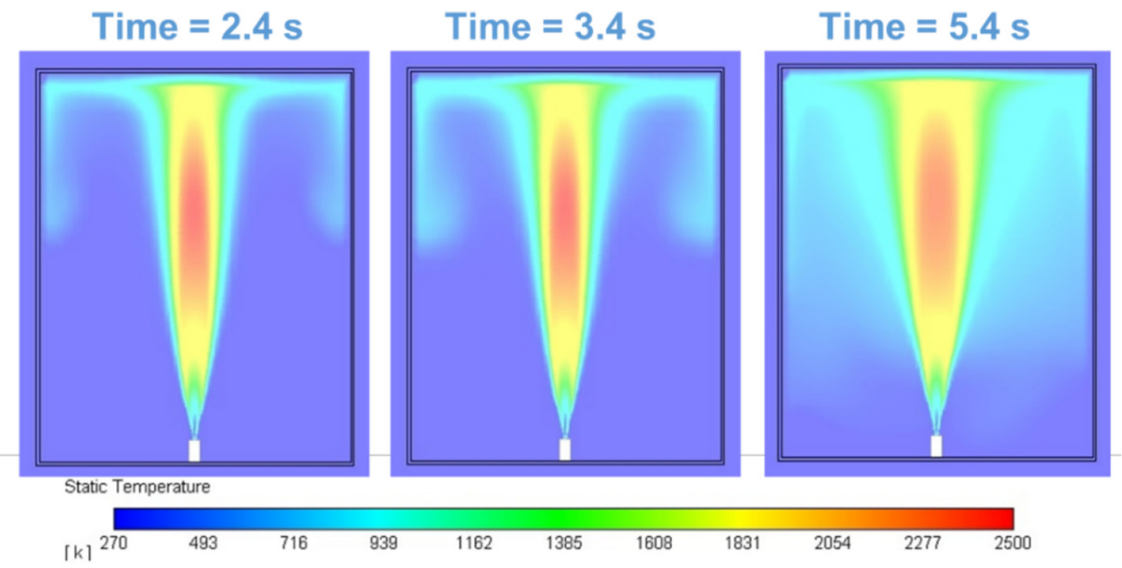

(b) Temperature, $\mathrm{K}$

Figure 4. (a) Simulated hydroxyl mole fraction and (b) temperature distributions in the plane $x=0$ perpendicular to the enclosure walls with vents for Test No.14 $\left(P_{S}=11.78 \mathrm{MPa}, \dot{m}=11.37 \mathrm{~g} / \mathrm{s}\right.$, Number of experimental vents $=3), \Delta t=0.34 \mathrm{~ms}, \mathrm{CFL}=50$. 
Four experimental thermocouples were located close to the enclosure walls to assess the thermal load on the structure (see Figure 1). The thermocouples were coated with protective Inconel alloy, which would affect their response time due to heat transfer through the Inconel layer. On the other hand, numerical simulations provide the instantaneous "non-inertial" temperature of the hot combustion gases, preventing a direct comparison with experimental measurements and requiring the data manipulation to include heat transfer through the sensors' Inconel layer. This process may be affected by inaccuracies rendering the comparison not reliable and, for this reason, this analysis is omitted.

The calculation time for simulations of $1 \mathrm{~s}$ is approximately $45 \mathrm{~h}$ with a time step of $0.34 \mathrm{~ms}$ on a $60 \mathrm{CPU}$ workstation. Thus, the calculation time for a complete release simulation is approximately two weeks. The numerical grid employing $1 \times 1 \mathrm{CV}$ to discretise the inflow boundary allows the use of a larger time step while maintaining the same CFL number due to the larger cell size at the release area. Simulations are performed by using a time step equal to $0.5 \mathrm{~ms}(\mathrm{CFL}=50)$ or $0.25 \mathrm{~ms}(\mathrm{CFL}=25)$. Figure 3 shows the resulting overpressure dynamics for both grids and nozzle resolutions. The maximum variation in the simulated pressure peaks was within $0.5 \%$, confirming the independence of the grid resolution at the inflow boundary for the same CFL number. The simulation time was $30 \mathrm{~h}$ for $1 \mathrm{~s}$ of hydrogen release, which is not yet sufficient to have a time-efficient and accurate calculation strategy.

\subsection{Volumetric Source Model Approach}

To further reduce the calculation time without affecting the solution accuracy, a volumetric source model is used to simulate hydrogen release. As the first step, the analysis is conducted to find convergence by CFL number. This was changed in the range 0.37-50.0, which corresponds to the time step range $0.12-16 \mathrm{~ms}$. Figure 5 shows the resulting overpressure dynamics for the CFL number in the range 0.37-3.0. It can be observed that variation in simulated pressure dynamics from experimental measurement decreases with the decrease of CFL. The calculated pressure peaks are $20.37 \mathrm{kPa}$ and $20.86 \mathrm{kPa}$ (approximately $2 \%$ relative difference) for CFL numbers $1.5(\Delta t=0.5 \mathrm{~ms})$ and $0.75(\Delta t=0.25 \mathrm{~ms})$ respectively. $\mathrm{A}$ further decrease of CFL to $0.37(\Delta t=0.125 \mathrm{~ms})$ results in a pressure peak equal to $21.00 \mathrm{kPa}$, which is higher by merely $0.7 \%$ than the pressure peak for $C F L=0.75$. Thus, a $C F L=0.75$ is deemed to lead to a converged solution while maintaining an acceptable calculation time of $17 \mathrm{~h}$ to simulate $1 \mathrm{~s}$ of hydrogen release. With the volumetric source model, the simulations of a test can be completed in approximately 5 days, which is a significant decrease in calculation time compared to the case employing the notional nozzle exit as the inflow boundary (approximately 2 weeks). A CFL $=0.75$ is applied for the rest of the simulations. The calculated pressure peak is $20.9 \mathrm{kPa}$, which agrees well with the experimentally measured peak pressure of $21.1 \mathrm{kPa}$. Figure 5 shows that the pressure dynamics is reproduced well, even though a slight difference towards the descending phase of the curve can be noticed. Once the release of hydrogen is stopped, the computational time step size was gradually increased with the same procedure as described for the notional nozzle exit inflow boundary modelling approach. Simulated negative overpressure decreases to approximately $-3 \mathrm{kPa}$, whereas about $-4 \mathrm{kPa}$ was measured in the experiment. The effect of the number of iterations per time step is assessed by increasing it from 20 to 40 . A variation of about $2 \%$ in the simulated pressure peak is observed, thus confirming the good accuracy of a solution with 20 iterations per time step. This value is maintained in the simulations. 


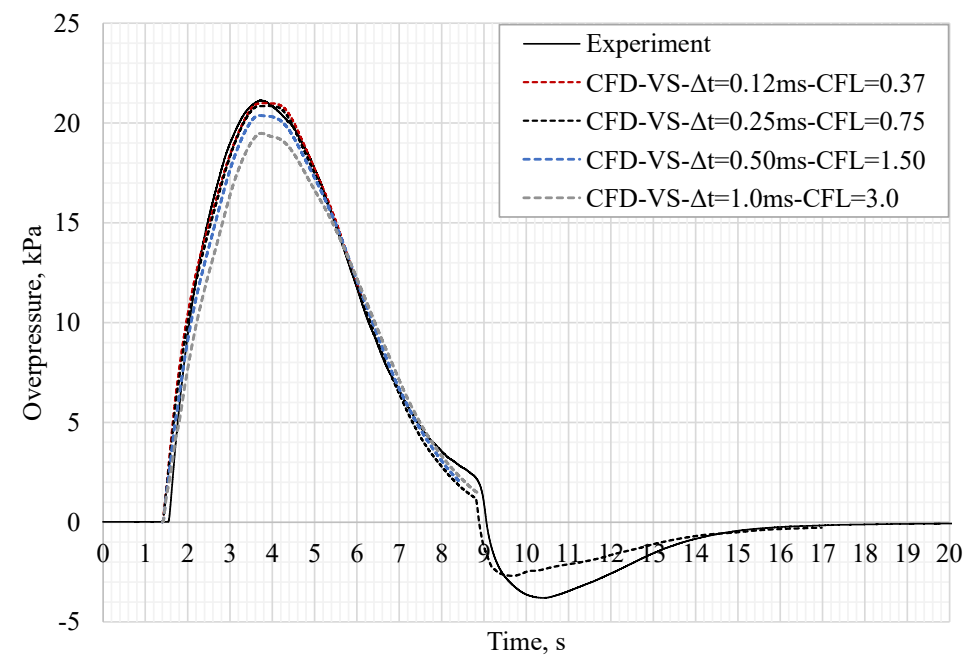

Figure 5. Simulated pressure dynamics in the enclosure and convergence by CFL number with the volumetric source model versus experimental pressure transient for Test No.14 $\left(P_{S}=11.78 \mathrm{MPa}\right.$, $\dot{m}=11.37 \mathrm{~g} / \mathrm{s}$, Number of experimental vents $=3$ ).

The described above CFD model is used then to simulate Tests No.18 and No.19. Figure 6 shows the comparison between the experimental and simulated pressure dynamics in the enclosure. The simulated pressure peak for Test No.18 is $35.10 \mathrm{kPa}$, which conservatively predicts the experimentally measured $33.22 \mathrm{kPa}$ with $7 \%$ accuracy. On the other hand, simulated overpressure in the enclosure for Test No.19 reaches the maximum value of $42.21 \mathrm{kPa}$, which underpredicts the experimental pressure peak of $48.1 \mathrm{kPa}$ by $14 \%$. This variation is considered to be acceptable in the engineering calculations of such phenomenon. The dynamics and magnitude of the negative pressure phase are well reproduced for both Tests No.18 and No.19. However, it can be observed that the maximum negative pressure for Test No.19 simulation is achieved $4 \mathrm{~s}$ earlier than in the experiment. The last is though due to the absence of water vapour condensation in the CFD model.

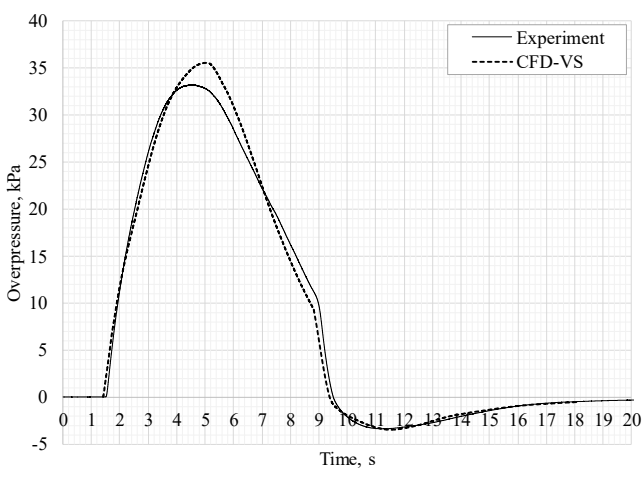

(a) Test No.18

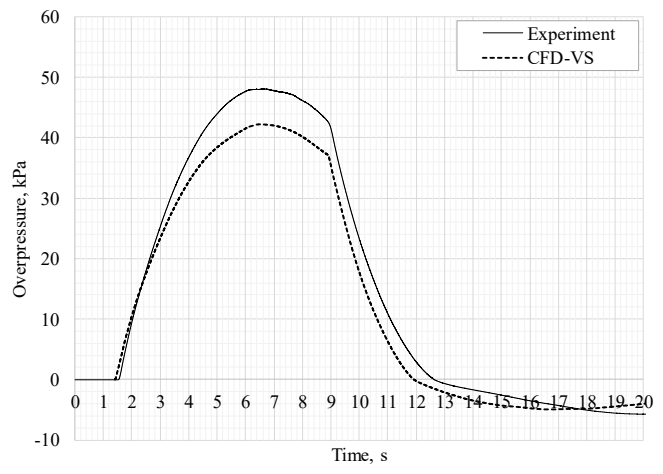

(b) Test No.19

Figure 6. Pressure dynamics in the enclosure: CFD simulations with $\mathrm{CFL}=0.75$ versus experiments: (a) Test No.18 $\left(P_{S}=12.46 \mathrm{MPa}, \dot{m}=11.47 \mathrm{~g} / \mathrm{s}\right.$, Number of experimental vents $\left.=2\right)$; (b) Test No.19 $\left(P_{S}=8.93 \mathrm{MPa}, \dot{m}=8.62 \mathrm{~g} / \mathrm{s}\right.$, Number of experimental vents $\left.=1\right)$.

\subsubsection{Effect of Heat Transfer to the Enclosure Walls}

The effect of heat transfer on pressure dynamics is assessed by comparing simulations for adiabatic and thermally conductive enclosure walls, see Figure 7. In both cases, radiative heat transfer from the jet fire is included through the DO model. Pressure peak slightly increases from $20.86 \mathrm{kPa}$ to $21.05 \mathrm{kPa}$ when heat losses are not included in the model, which is considered to be a negligible effect on the pressure peak and pressure dynamics. 
This result confirms the conclusion drawn in [10] that the heat transfer to the walls has a negligible effect on the positive phase of the overpressure dynamics. The negative phase may be affected by condensation of water vapour at the enclosure walls, which will be dependent on the heat transfer.

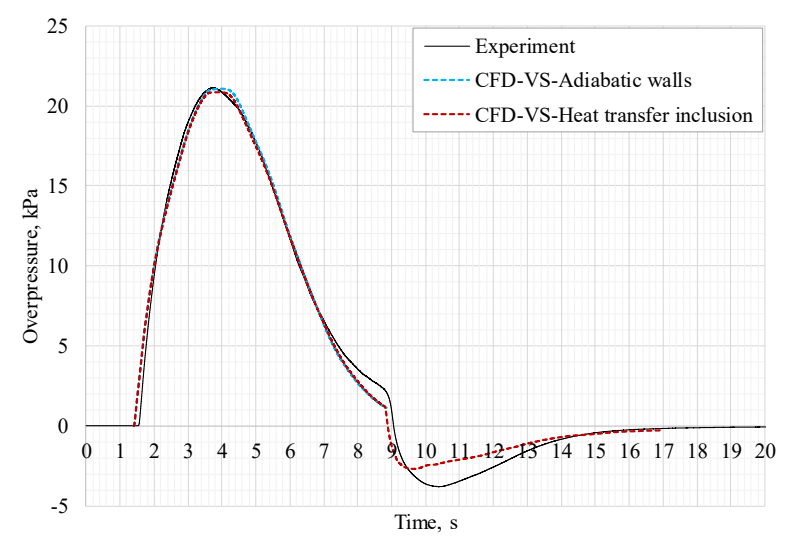

Figure 7. Pressure dynamics in the enclosure for Test No.14 $\left(P_{S}=11.78 \mathrm{MPa}, \dot{m}=11.37 \mathrm{~g} / \mathrm{s}\right.$, Number of experimental vents $=3$ ): effect of heat transfer to the enclosure walls.

\subsubsection{Time-Efficient Approach of the Uniform Cube-Shaped Control Volumes Grid}

The use of a volumetric source model is found, as demonstrated above, to reduce significantly the calculation time by approximately a factor of 3 . In this section, a novel and simplified approach is developed to further enhance the time efficiency of calculations while maintaining an acceptable solution accuracy. This is based on the building of a uniform hexahedral grid throughout the calculation domain with the same size as the vent $(7 \mathrm{~cm}$ square opening). The volumetric source is modelled as a cube with a $7 \mathrm{~cm}$ side. This dimension corresponds to approximately eight times the notional nozzle diameter. The CV number in the domain is 317,878 . Maintaining the same CFL $=0.75$ at the release area for this grid increases time step by three times $(\Delta t=0.75 \mathrm{~ms})$. Thus, it is expected to significantly decrease the computational time.

Figure 8a shows the pressure dynamics for Test No.14. A larger volumetric source results in a larger simulated overpressure $(22.66 \mathrm{kPa})$ by approximately $8 \%$ relative difference, whereas the negative phase is simulated similarly. The hydrogen mass flow rate provided by the volumetric source (VS) is monitored. Maximum variation of released hydrogen between the two VS sizes, respectively 3.8 and $7.0 \mathrm{~cm}$, is calculated to be within $0.7 \%$. However, even though the hydrogen mass flow rate is maintained nearly the same for both cases, the distribution of hydrogen, combustion products and temperature can vary greatly, affecting as a consequence the composition and density of gases exiting the enclosure and the reached overpressure. A lower volumetric flow rate through the vents is observed for the simplified approach with uniform CV size $7 \mathrm{~cm}$. All the above could be a direct consequence of the application of the volumetric source approach beyond the validity range stated in [18] and the use of a coarser grid. Calculation time is approximately $6 \mathrm{~h}$ to simulate $1 \mathrm{~s}$ of hydrogen release. With full understanding of the simplified approach limitations, this is seen as a pragmatic way to reduce the calculation time by approximately a factor of 3. Thus, the authors yet consider the simplified approach as valuable for PPP prediction to obtain time efficient calculations. However, it should be highlighted that the reduction of computational time may come at a cost of a lower accuracy of calculations that should be maintained within reasonable for engineering applications precision. 


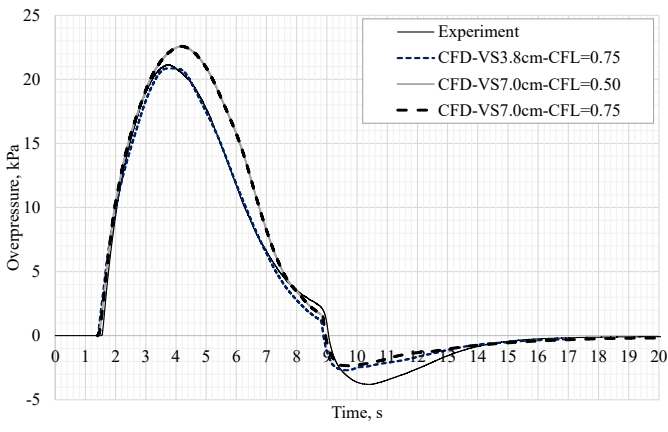

(a) Test No.14

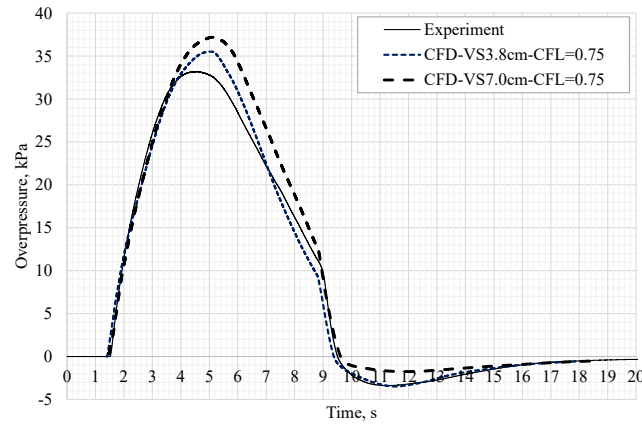

(b) Test No.18

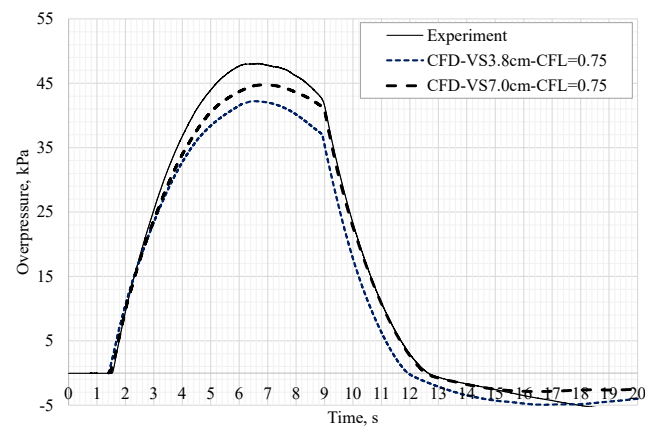

(c) Test No.19

Figure 8. Pressure dynamics in the enclosure for the unified "cube grid" approach (VS7.0 cm): (a) Test No.14 $\left(P_{S}=11.78 \mathrm{MPa}, \dot{m}=11.37 \mathrm{~g} / \mathrm{s}\right.$, Number of vents $\left.=3\right)$; $(\mathbf{b})$ Test No.18 $\left(P_{S}=12.46 \mathrm{MPa}\right.$, $\dot{m}=11.47 \mathrm{~g} / \mathrm{s}$, Number of vents $=2) ;($ c $)$ Test No.19 $\left(P_{S}=8.93 \mathrm{MPa}, \dot{m}=8.62 \mathrm{~g} / \mathrm{s}\right.$, Number of vents =1).

The CFL independence of a solution for the volumetric source (VS) model with uniform "cube grid" of $7.0 \mathrm{~cm}$ size was assessed for Test No.14 for CFL number 0.50 and 0.75 (see Figure 8a). The pressure dynamics is not affected by the CFL number change by $50 \%$. Thus, the CFL $=0.75$ was maintained for the simulations using the "cube grid". Figure 8 b,c show the overpressure dynamics for Test No.18 and Test No.19 respectively. Maximum pressure for Test No.18 demonstrates variation by $+5.8 \%$, i.e., the increase from $35.10 \mathrm{kPa}$ for a VS size $3.8 \mathrm{~cm}$ to $37.20 \mathrm{kPa}$ for VS size $7.0 \mathrm{~cm}$, and the difference of maximum overpressure simulated for $\mathrm{VS}=7.0 \mathrm{~cm}$ from the experimentally measured value is $+11 \%$ (conservative). For Test No.19, the simulated overpressure peak with VS $=3.8 \mathrm{~cm}$ underestimates experimental measurement by $-14 \%$, whereas the case with VS $=7.0 \mathrm{~cm}$ differs from experiments by only $-7.4 \%$. Conversely to what is observed for Test No.14, the negative pressure in Tests No.18 and No.19 is affected by the change of VS modelling approach, resulting in approximately half of the maximum negative pressure recorded in experiments when the VS $=7.0 \mathrm{~cm}$ approach is employed. Simulation results on the maximum overpressure peaks for the two approaches VS $=3.8 \mathrm{~cm}$ and VS $=7.0$ are summarized and compared to experiments in Table 3.

Table 3. Comparison of the experimentally measured maximum overpressure peaks to simulation results for the employed volumetric source approaches (in brackets relative difference from experiments).

\begin{tabular}{cccc}
\hline \multirow{2}{*}{ Test No. } & $\begin{array}{c}\text { Experimental Maximum } \\
\text { Overpressure, kPa }\end{array}$ & \multicolumn{2}{c}{ Simulated Maximum Overpressure, kPa } \\
\cline { 3 - 4 } & 21.1 & $20.9(-1 \%)$ & VS = 7.0 cm \\
\hline 14 & 33.2 & $35.1(+5 \%)$ & $22.7(+7 \%)$ \\
\hline 18 & 48.1 & $42.2(-14 \%)$ & $37.2(+11 \%)$ \\
\hline 19 & & & $44.8(-7 \%)$ \\
\hline
\end{tabular}


The simplified uniform "cube grid" VS $=7.0 \mathrm{~cm}$ approach is seen to reduce significantly the calculation time by approximately 3 times compared to the VS $=3.8 \mathrm{~cm}$ approach, and by approximately 7.5 times compared to the previously used notional nozzle exit approach for hydrogen inflow boundary. The accuracy of the maximum simulated overpressure is found to be $\pm 11 \%$. This is well within the acceptable engineering accuracy for such complex phenomenon. It can be concluded that the unified "cube grid" VS $=7.0 \mathrm{~cm}$ approach is a valuable hydrogen safety engineering tool for the assessment of the pressure peaking phenomenon.

Both the inflow boundary at the notional nozzle exit and volumetric source approaches are seen to represent well experiments with storage pressure up to $12.5 \mathrm{MPa}$ and hydrogen mass flow rate up to $11.5 \mathrm{~g} / \mathrm{s}$. The validation domain of the CFD model is not limited by storage pressure but is defined by the released mass flow rate, being this the key input for PPP. A release of hydrogen from a storage with pressure $12.5 \mathrm{MPa}$ and TPRD diameter of $4 \mathrm{~mm}$ would be equivalent to a release from a $70 \mathrm{MPa}$ storage and $0.65 \mathrm{~mm}$ TPRD diameter, as calculated through e-Laboratory developed within NET-Tools project [26] (11.5 g/s for conservative $C_{d}=1$ ). Thus, the conclusions of the present study are valid for current onboard storage systems with such TPRD diameter and the CFD model can be applied for the associated safety assessments.

\subsection{Effect of Cryogenic Storage Temperature on the Pressure Peaking Phenomenon}

Hydrogen may be stored in cryo-compressed conditions, i.e., storage temperature below $120 \mathrm{~K}$ as generally considered for cryogenics [27] and pressure up to $35 \mathrm{MPa}$ [28]. Cryogenic storage pressure below $20 \mathrm{MPa}$ is considered to provide a better gain in gravimetric and volumetric capacities against the energy required for the compression and cooling down of the hydrogen gas. With the increase of storage pressures above $20 \mathrm{MPa}$, these benefits are seen to reduce [29].

This section assesses the effect of hydrogen storage temperature on the PPP dynamics for the same enclosure and the volumetric source model approach with VS size $3.8 \mathrm{~cm}$ and $\mathrm{CFL}=0.75$ (see detailed description in Section 4.2) is used for the cases listed in Table 4. Simulations include the effect of heat transfer through the enclosure walls. The selected scenario is that of Test No.14, i.e., storage pressure $11.78 \mathrm{MPa}$, nozzle diameter $4 \mathrm{~mm}$ and constant hydrogen mass flow rate. All three experimental vents of the enclosure are simulated as fully open. The storage temperature, $T_{S}$, is varied from ambient $277 \mathrm{~K}$, as per Test No.14, to an intermediate temperature of $200 \mathrm{~K}$ and to cryogenic temperature of $100 \mathrm{~K}$. Four cases of hydrogen releases at a storage temperature lower than atmospheric are simulated and details are given in Table 4 along Test No.14 data. Effect of heat transfer through the release pipe walls is not taken into account to isolate the effect of storage temperature on the pressure peak. Parameters at the notional nozzle exit are calculated as in [30], i.e., through the under-expanded jet theory implementing the NIST database [31] using the Helmholtz Free Energy EOS. The calculated notional nozzle parameters are used to define the source terms in the volumetric source approach. It is considered that the potential for hydrogen phase change during expansion of cryo-compressed hydrogen can be neglected for this range of applications and the CFD model. Table 4 shows that conditions at the notional nozzle exit would be above hydrogen critical point. Furthermore, the volumetric source approach was seen in [32] to well reproduce experimental temperature distribution for a transient hydrogen unignited jet from a storage with initial pressure and temperature equal to $20 \mathrm{MPa}$ and $80 \mathrm{~K}$ respectively [33]. Cases 2 and 3 maintain the same storage pressure, pipe diameter of $4 \mathrm{~mm}$ and discharge coefficient as per Test No.14. The decrease of temperature causes an increase of released hydrogen mass flow rate from $11.37 \mathrm{~g} / \mathrm{s}$ for $T_{S}=277 \mathrm{~K}$, to $14.11 \mathrm{~g} / \mathrm{s}$ for $T_{S}=200 \mathrm{~K}$ and $23.16 \mathrm{~g} / \mathrm{s}$ for $T_{S}=100 \mathrm{~K}$. Cases 4 and 5 consider the effect of storage temperature on the PPP dynamics for scenarios of the same storage pressure and the same mass flow rate as per Case 1 (Test No.14). For releases at ambient temperature, the PPP magnitude depends on the released mass flow rate of hydrogen for unvaried enclosure volume and vent area. This analysis aims at quantifying 
the sole effect of cryogenic hydrogen temperature at the release on the combustion products temperature and enthalpy, and, thus, on the resulting maximum overpressure peak. To match the same mass flow rate as in Test No.14 (Case 1) the discharge coefficient is reduced for the Cases 4 and 5 at cryogenic temperatures. This is equivalent to reducing the pipe diameter, as the mass flow rate is proportional to the product of discharge coefficient and pipe cross section area being proportional to diameter squared. The change in calculated notional nozzle diameters, $D_{N N}$, in cases 4 and 5 is due to the application of NIST EOS which provides larger densities for cryogenic hydrogen compared to the Abel Noble EOS employed for case 1 at ambient temperature.

Table 4. Simulations to assess effect of storage temperature on PPP: storage, release and notional nozzle conditions.

\begin{tabular}{|c|c|c|c|c|c|c|c|c|}
\hline Case & $\begin{array}{c}\text { Storage } \\
\text { Pressure, MPa }\end{array}$ & $\begin{array}{c}\text { Storage } \\
\text { Temperature, K }\end{array}$ & $C_{d}$ & $\begin{array}{l}\text { Constant Mass } \\
\text { Flow Rate } \mathrm{H}_{2}, \mathrm{~g} / \mathrm{s}\end{array}$ & $D_{N N}, \mathrm{~mm}$ & $T_{N N}, \mathrm{~K}$ & $U_{N N}, \mathrm{~m} / \mathrm{s}$ & $\begin{array}{l}\text { Pressure } \\
\text { Peak, kPa }\end{array}$ \\
\hline $\begin{array}{l}1 \text { (Test } \\
\text { No.14) }\end{array}$ & 11.78 & 277 & 0.13 & 11.37 & 11.0 & 230.8 & 1154.5 & 20.95 \\
\hline 2 & 11.78 & 200 & 0.13 & 14.11 & 10.8 & 145.0 & 915.1 & 26.95 \\
\hline 3 & 11.78 & 100 & 0.13 & 23.16 & 11.1 & 67.3 & 623.3 & 42.82 \\
\hline 4 & 11.78 & 200 & 0.10 & 11.37 & 9.7 & 145.0 & 915.1 & 20.51 \\
\hline 5 & 11.78 & 100 & 0.06 & 11.37 & 7.8 & 67.3 & 623.3 & 19.96 \\
\hline
\end{tabular}

Figure 9 presents the resulting overpressure dynamics for the simulated cases (see Table 4). As expected, Cases 2 and 3 demonstrate a higher pressure peak than for case 1, due to the higher hydrogen mass flow rate (MFR) for the same storage pressure and discharge coefficient but lower storage temperature. The pressure peak recorded for Case 2 with storage temperature $T_{S}=200 \mathrm{~K}$ and MFR $=14.11 \mathrm{~g} / \mathrm{s}$ is $26.95 \mathrm{kPa}$. The pressure peak increases up to $42.82 \mathrm{kPa}$ for the Case $3\left(T_{S}=100 \mathrm{~K}, \mathrm{MFR}=23.16 \mathrm{~g} / \mathrm{s}\right)$. The higher is the positive pressure peak the higher is the negative pressure peak, which reaches $-5.36 \mathrm{kPa}$.

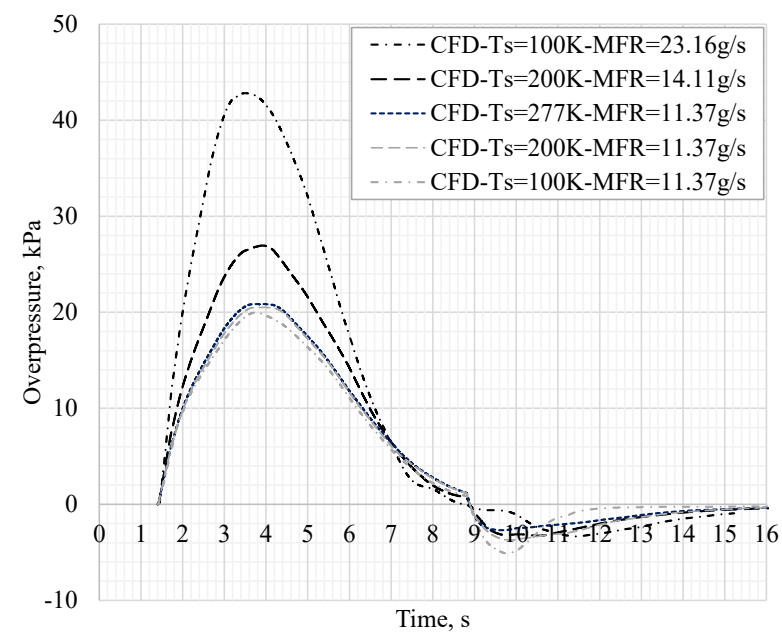

Figure 9. Effect of hydrogen storage temperature on the PPP dynamics in the enclosure with volume of $15 \mathrm{~m}^{3}$ and three vents with dimensions $7 \times 7 \mathrm{~cm}$.

It is expected that the higher pressure peak for cryogenic releases is associated with a larger difference between the volumetric flow rate entering the enclosure, due to the larger hydrogen MFR and its combustion, and the volumetric flow rate of gases exiting the enclosure through vents. To confirm this generic concept, two limiting cases, i.e., Case 1 $\left(T_{S}=277 \mathrm{~K}\right)$ and Case $3\left(T_{S}=100 \mathrm{~K}\right)$ are compared. The assessment is based on the PPP theory for ignited hydrogen releases [7]. For the complete combustion of hydrogen in air, 
the volumetric flow rate "entering" the enclosure is determined by "competition" between the rate of consumption of cold hydrogen and enclosure air during combustion, and the rate of generation of hot combustion products in reaction at adiabatic flame temperature, $T_{a d}$. For an arbitrary molar flow rate of hydrogen and assuming an isobaric combustion at atmospheric pressure, the balance of gas volume consumption and generation associated with hydrogen combustion in air can be written as [7]:

$$
\dot{V}_{c, \text { in }}=\frac{\dot{m}_{H_{2}}}{M_{H_{2}}} \frac{R T_{a d}}{P}+\frac{3.76}{2} \frac{\dot{m}_{H_{2}}}{M_{H_{2}}} \frac{R T_{a d}}{P}-\frac{(1+3.76)}{2} \frac{\dot{m}_{\mathrm{H}_{2}}}{M_{\mathrm{H}_{2}}} \frac{R T_{0}}{P}-\frac{\dot{m}_{\mathrm{H}_{2}}}{M_{\mathrm{H}_{2}}} \frac{R T_{0}}{P}=\frac{\dot{m}_{\mathrm{H}_{2}}}{M_{\mathrm{H}_{2}}} \frac{R T_{0}}{P}\left(\frac{T_{a d}}{T_{0}}+\frac{3.76}{2} \frac{T_{a d}}{T_{0}}-\frac{1+3.76}{2}-1\right),
$$

where $M_{\mathrm{H}_{2}}$ is the hydrogen molar mass ( $\left.2 \mathrm{~kg} / \mathrm{kmol}\right), R$ is the universal gas constant $(8314.4 \mathrm{~J} / \mathrm{kmol} / \mathrm{K})$ and $P$ is the ambient pressure. $T_{0}$ is the initial temperature of the mixture of hydrogen at notional nozzle temperature, $T_{N N}$, and air at ambient temperature, $T_{a m b}$. The conservation of enthalpy is used to calculate $T_{0}$ as follows:

$$
c_{p, \text { mix }}\left(m_{H 2}+m_{\text {air }}\right) T_{0}=c_{p, H 2} m_{H 2} T_{N N}+c_{p, a i r} m_{a i r} T_{a m b} .
$$

Table 5 shows the parameters calculated for the selected Cases 1 and 3. A diffusion flame consumes reactants at a stochiometric composition, meaning that a mole of hydrogen requires 2.38 mole of air. This corresponds to $1 \mathrm{~g}$ of hydrogen, $m_{\mathrm{H} 2}$ in Equation (3), consuming $34.8 \mathrm{~g}$ of air, $m_{\text {air }}$ in Equation (3). Ambient temperature, $T_{a m b}$, is $277 \mathrm{~K}$. The specific heat for air, $c_{p, a i r}$, is equal to $1010 \mathrm{~J} / \mathrm{kgK}$, whereas the specific heat for hydrogen, $c_{p, H 2}$, is obtained from NIST Chemistry WebBook [31]. Thus, $T_{0}$ is calculated as $263.8 \mathrm{~K}$ and $228.1 \mathrm{~K}$ for $T_{S}$ equal to $277 \mathrm{~K}$ and $100 \mathrm{~K}$, respectively.

Table 5. Effect of storage temperature on combustion parameters and volumetric flow rate balance for limiting cases 1 and 3 .

\begin{tabular}{ccccccccc}
\hline Case & $T_{S}, \mathbf{K}$ & Mass Flow Rate $\dot{m}_{H_{2}}, \mathbf{g} / \mathbf{s}$ & $T_{N N}, \mathbf{K}$ & $T_{0}, \mathbf{K}$ & $T_{a d}, \mathbf{K}$ & $\frac{\dot{m}_{H_{2}}}{M_{H_{2}}} \frac{R T_{0}}{P}, \mathbf{m}^{3} / \mathbf{s}:$ & $\alpha$ & $\dot{V}_{c, i n}, \mathbf{m}^{3} / \mathbf{s}$ \\
\hline 1 & 277 & 11.37 & 230.8 & 263.8 & 2370.9 & 0.123 & 22.5 & 2.77 \\
\hline 3 & 100 & 23.16 & 67.3 & 228.1 & 2351.9 & 0.217 & 26.3 & 5.70 \\
\hline
\end{tabular}

A minor effect of hydrogen storage temperature is observed on $T_{a d}$, which presents a difference of approximately $20 \mathrm{~K}$. The multiplier $\alpha=\left(\frac{T_{a d}}{T_{0}}+\frac{3.76}{2} \frac{T_{a d}}{T_{0}}-\frac{1+3.76}{2}-1\right)$ represents the difference between the volumetric flow rate of the unignited release and the ignited release (jet fire) from the same source [7]. The term $\alpha$ increases from 22.5 for $T_{S}=277 \mathrm{~K}$ to 26.3 for $T_{S}=100 \mathrm{~K}$. The variation in $\alpha$ and the more significant double increase in mass flow rate for decreasing storage temperature, cause the volumetric flow rate "entering" the enclosure, i.e., the volumetric flow rate resulting from the combustion of the released hydrogen in air, to rise from $2.77 \mathrm{~m}^{3} / \mathrm{s}$ to $5.70 \mathrm{~m}^{3} / \mathrm{s}$. Figure 10 compares the calculated inlet volumetric flow rate resulting from combustion, $\dot{V}_{c, i n}$, and the simulated volumetric flow rate exiting the enclosure through the three vents $\dot{V}_{v, \text { out }}$. It can be observed that for $T_{s}=277 \mathrm{~K}$, the maximum $\dot{V}_{v, \text { out }}$ almost equalises $\dot{V}_{c, i n}$. On the other hand, for $T_{s}=100 \mathrm{~K}, \dot{V}_{c, i n}$ is almost twice the volumetric flow rate going out from the enclosure, and this is the cause for the higher overpressure recorded in the enclosure.

Cases 4 and 5 investigate the effect of only hydrogen storage temperature on the pressure peaking phenomenon while maintaining the same storage pressure and mass of released hydrogen as in Case 1 by reducing the discharge coefficient. Reduction of temperature leads to a slight decrease of pressure peak in the enclosure from $20.95 \mathrm{kPa}$ for $T_{S}=277 \mathrm{~K}$ to $20.51 \mathrm{kPa}$ for $T_{S}=200 \mathrm{~K}$ and to $19.96 \mathrm{kPa}$ for $T_{S}=100 \mathrm{~K}$ if the mass flow rate $(11.37 \mathrm{~g} / \mathrm{s})$ and the storage pressure $(11.78 \mathrm{MPa})$ are kept the same. This result is expected as a decrease of the hydrogen temperature mixing with air would lead to 
a decrease of combustion temperature. As a consequence, after stopping the hydrogen release, combustion products cool down faster for lower hydrogen release temperature. This causes a more pronounced negative pressure as shown in Figure 9.

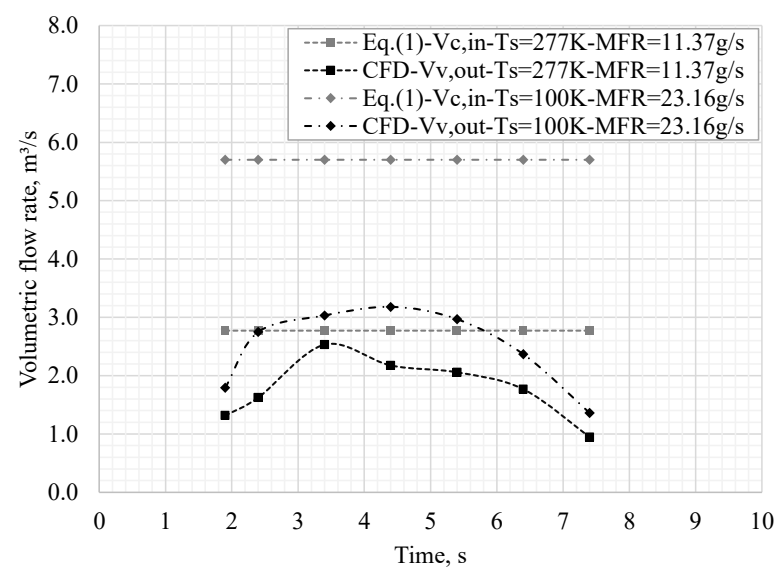

Figure 10. Effect of hydrogen storage temperature on volumetric flow rates entering and exiting the enclosure for the two limiting cases $1\left(T_{S}=277 \mathrm{~K}\right)$ and $3\left(T_{S}=100 \mathrm{~K}\right)$.

It can be concluded that for the same storage pressure and hydrogen mass flow rate (requires, in general case, the decrease of piping diameter for lower temperature), the decrease in storage temperature causes the decrease of enthalpy associated to the entering hydrogen, see Equation (2), and, thus, only a slight reduction of the PPP overpressure in the enclosure. On the other hand, for the same storage pressure, and the same piping system (with the same discharge coefficient) resulting in the increased hydrogen mass flow rate for lower temperature, causes, as a consequence, the increase of the pressure peak in the storage enclosure. As an example, it is observed that for a storage pressure of $11.78 \mathrm{MPa}$, the hydrogen mass flow rate increases from $11.37 \mathrm{~g} / \mathrm{s}$ for $T_{S}=277 \mathrm{~K}$ to $23.16 \mathrm{~g} / \mathrm{s}$ for $T_{S}=100 \mathrm{~K}$. Such a variation in mass flow rate leads to a twofold increase in the pressure peak from $20.95 \mathrm{kPa}$ to $42.82 \mathrm{kPa}$.

\section{Conclusions}

The significance of this work is the development and validation of the time-efficient CFD model as a contemporary engineering tool for hydrogen safety engineering. The unique experiments on the pressure peaking phenomenon (PPP) for ignited hydrogen releases at storage pressures up to $12 \mathrm{MPa}$ in a large-scale $15 \mathrm{~m}^{3}$ enclosure are used to develop and validate the CFD model. The conclusions of the work and CFD model are valid for current onboard storage systems with storage pressure $70 \mathrm{MPa}$ and TPRD diameter up to $0.65 \mathrm{~mm}$.

The originality of the study lies in the further development of the CFD model by the application of the volumetric source model capable to drastically improve the time efficiency of computations. Two approaches to model hydrogen release in terms of predictive capability and computational performance are compared: the widely used notional nozzle exit inflow boundary approach and the volumetric source approaches. The volumetric source model allowed a threefold decrease of the simulations time compared to the notional nozzle approach. To further reduce the computational time, a unified size throughout the domain "cube grid" approach employing a volumetric source model was developed. This approach is found to well reproduce the experimental pressure dynamics with $\pm 11 \%$ accuracy while reducing the computational time by approximately a factor of 7.5 in comparison to the "standard" notional nozzle exit inflow boundary approach.

The developed and validated CFD model was then applied to assess the effect of hydrogen storage temperature in the range from atmospheric to cryogenic temperatures on the pressure peaking phenomenon. The decrease of storage temperature for the same 
storage pressure and discharge coefficient caused an increase in hydrogen mass flow rate, and, thus, a higher overpressure peak. It was found that for the storage pressure of $11.78 \mathrm{MPa}$, the overpressure peak increased from $20.95 \mathrm{kPa}$ to $42.82 \mathrm{kPa}$ for a temperature drop from $277 \mathrm{~K}$ to $100 \mathrm{~K}$. This effect should be accounted for in the design of safety systems for release from cryo-compressed hydrogen storage.

The validation of the CFD model against large-scale experiments underpins the rigour of the study. The work expanded the validation domain of the CFD model from enclosures with the free volume of about $1 \mathrm{~m}^{3}$ with release at hydrogen mass flow rates up to $1.1 \mathrm{~g} / \mathrm{s}$ [10] to the volume of $15 \mathrm{~m}^{3}$ and mass flow rate up to $11.5 \mathrm{~g} / \mathrm{s}$ in this study with the generation of pressure as large as $48 \mathrm{kPa}$ well above 10-20 kPa that civil structures could withstand. The simulated pressure dynamics and maximum overpressure are found to agree well with experimental data. For example, the deviation of simulations from experimental pressure was within $\pm 5 \%$ for Test No.14 with storage pressure of $11.78 \mathrm{MPa}$ and hydrogen mass flow rate of $11.37 \mathrm{~g} / \mathrm{s}$. Heat transfer to and through the enclosure walls is found not to affect significantly the resulting overpressure peak, confirming previous observations [10].

Author Contributions: Conceptualization, D.C., D.M. and V.M.; methodology, D.C., D.M. and V.M.; software, D.C.; validation, D.C., D.M. and V.M.; formal analysis, D.C., D.M., V.M., A.W.L. and A.V.G.; investigation, D.C., D.M., V.M., A.W.L. and A.V.G.; resources, D.C., D.M., V.M., A.W.L. and A.V.G.; data curation, D.C., D.M., V.M., A.W.L. and A.V.G.; writing-original draft preparation, D.C.; writing—review and editing, D.C., D.M., V.M., A.W.L. and A.V.G.; visualization, D.C., D.M. and V.M.; supervision, V.M. and D.M.; project administration, V.M. and D.M.; funding acquisition, V.M. All authors have read and agreed to the published version of the manuscript.

Funding: This research has received funding from the Fuel Cells and Hydrogen 2 Joint Undertaking under grant agreement No. 826193 (HyTunnel-CS) and No. 779613 (PRESLHY). The JU receives support from the European Union's Horizon 2020 research and innovation programme and the United Kingdom, Germany, Greece, Denmark, Spain, Italy, Netherlands, Belgium, France, Norway, Switzerland. The authors would like to acknowledge EPSRC for funding the project Kelvin-2 “Tier 2 High-Performance Computing Services", EP/T022175/1.

Institutional Review Board Statement: Not applicable.

Informed Consent Statement: Not applicable.

Data Availability Statement: The data presented in this study are publicly available in the cited references.

Conflicts of Interest: The authors declare no conflict of interest. The funders had no role in the design of the study; in the collection, analyses, or interpretation of data; in the writing of the manuscript, or in the decision to publish the results.

\section{References}

1. IEA Fuel Cell Electric Vehicle Stock by Segment, 2017-2020. Available online: https:/ /www.iea.org/data-and-statistics/charts / fuel-cell-electric-vehicle-stock-by-segment-2017-2020 (accessed on 16 December 2021).

2. Veenstra, M.J.; Hobein, B. On-Board Physical Based 70 MPa Hydrogen Storage Systems. SAE Int. J. Engines 2011, 4, $1862-1871$. [CrossRef]

3. United Nations Economic Commission for Europe Global Registry. Addendum 13: Global techni.cal reg.ulation No. 13. Global Technical Regulation on Hydrogen and Fuel Cell Vehicles; UNECE: Geneva, Switzerland, 2013.

4. Brennan, S.; Makarov, D.; Molkov, V. Dynamics of Flammable Hydrogen-Air Mixture Formation in an Enclosure with a Single Vent. In Proceedings of the Sixth International Seminar on Fire and Explosion Hazards, Leeds, UK, 11-16 April 2010.

5. Brennan, S.; Molkov, V. Safety assessment of unignited hydrogen discharge from onboard storage in garages with low levels of natural ventilation. Int. J. Hydrogen Energy 2013, 38, 8159-8166. [CrossRef]

6. Brennan, S.; Molkov, V. Pressure peaking phenomenon for indoor hydrogen releases. Int. J. Hydrogen Energy 2018, 43, 18530-18541. [CrossRef]

7. Makarov, D.; Shentsov, V.; Kuznetsov, M.; Molkov, V. Pressure peaking phenomenon: Model validation against unignited release and jet fire experiments. Int. J. Hydrogen Energy 2018, 43, 9454-9469. [CrossRef]

8. Lach, A.W.; Gaathaug, A.V.; Vaagsaether, K. Pressure peaking phenomena: Unignited hydrogen releases in confined spacesLarge-scale experiments. Int. J. Hydrogen Energy 2020, 45, 32702-32712. [CrossRef] 
9. Lach, A.W.; Gaathaug, A.V. Large scale experiments and model validation of Pressure Peaking Phenomena-ignited hydrogen releases. Int. J. Hydrogen Energy 2021, 46, 8317-8328. [CrossRef]

10. Hussein, H.G.; Brennan, S.; Shentsov, V.; Makarov, D.; Molkov, V. Numerical validation of pressure peaking from an ignited hydrogen releasein a laboratory-scale enclosure and application to a garage scenario. Int. J. Hydrogen Energy 2018, 43, 17954-17968. [CrossRef]

11. Brennan, S.; Hussein, H.G.; Makarov, D.; Shentsov, V.; Molkov, V. Pressure effects of an ignited release from onboard storage in a garage with a single vent. Int. J. Hydrogen Energy 2019, 8927-8934. [CrossRef]

12. DOE. Technical Assessment: Cryo-Compressed Hydrogen Storage for Vehicular Applications; 2006. Available online: https://www. energy.gov/sites/default/files/2014/03/f12/cryocomp_report.pdf (accessed on 15 February 2021).

13. Shih, T.H.; Liou, W.W.; Yang, A.; Shabbir, Z. A new eddy-viscosity model for high Reynolds number turbulent flows-Model development and validation. Comput. Fluids 1995, 24, 227-238. [CrossRef]

14. Cirrone, D.; Makarov, D.; Molkov, V. Thermal radiation from cryogenic hydrogen jet fires. Int. J. Hydrogen Energy 2019, 44, 8874-8885. [CrossRef]

15. Magnussen, B. On the structure of turbulence and a generalized eddy dissipation concept for chemical reaction in turbulent flow. In Proceedings of the 19th Aerospace Sciences Meeting, St. Louis, MO, USA, 12-15 January 1981.

16. Peters, N.; Rogg, B. Reduced Kinetic Mechanisms for Applications in Combustion Systems; Springer: Berlin/Heidelberg, Germany, 1993.

17. Murthy, J.Y.; Mathur, S.R. A finite volume method for radiative heat transfer using unstructured meshes. 36th AIAA Aerosp. Sci. Meet. Exhib. 1998, 12, 313-321. [CrossRef]

18. Molkov, V.; Makarov, V.; Bragin, M.V. Physics and modelling of underexpanded jets and hydrogen dispersion in atmosphere. Phys. Extrem. States Matter 2009, 146-149.

19. Engineers Edge, Thermal Properties of Metals, Conductivity, Thermal Expansion, Specific Heat. Available online: https: //www.engineersedge.com/properties_of_metals.htm (accessed on 2 February 2021).

20. Mikron Table of Emissivity of Various Surfaces. Available online: http://www-eng.lbl.gov/ \{\}dw/projects/DW4229_LHC_ detector_analysis/calculations/emissivity2.pdf (accessed on 15 February 2021).

21. Ansys Fluent. User's Guide; Ansys Inc.: Canonsburg, PA, USA, 2016.

22. Kee, R.J.; Rupley, F.M.; Miller, J.A.; Coltrin, M.E.; Grcar, J.F.; Meeks, E.; Moffat, H.K.; Lutz, A.E.; DixonLewis, G.; Smooke, M.D.; et al. The Chemkin Thermodynamic Database. In Chemkin Collection Release 3.6; Reaction Design: Diego, CA, USA, 2000; ISBN SAND87-8215B

23. Yates, D. Innovative Solutions to Reduce Separation Distances in On-Board Hydrogen Storage. Ph.D. Thesis, Ulster University, Coleraine, UK, 2016.

24. Schefer, R.; Houf, B.; Bourne, B.; Colton, J. Experimental Measurements to Characterize the Thermal and Radiation Properties of an Open-flame Hydrogen Plume. In Proceedings of the 15th Annual Hydrogen Conference and Hydrogen Expo, Los Angeles, CA, USA, 26-30 April 2004.

25. Cirrone, D.; Makarov, D.; Kuznetsov, M.; Friedrich, A.; Molkov, V. Effect of heat transfer through the release pipe on simulations of cryogenic hydrogen jet fires and hazard distances. In Proceedings of the International Conference on Hydrogen Safety, Edinburgh, Scotland, 21-24 September 2021.

26. NET-Tools Project Novel Education And Training Tools Based on Digital Applications Related to Hydrogen and Fuel Cell Technology; European Commision: Brussels, Belgium, 2017.

27. Radebaugh, R. Cryogenics. The MacMillan Encyclopedia of Chemistry. 2002. Available online: https://books.google.com.hk/ books?id=RDT-DwAAQBAJ\&pg=PA122\&lpg=PA122\&dq=27.\%09Radebaugh,+R.+Cryogenics.+MacMillan+Encycl.+Chem . $+2002++,+1 \%$ E2\%80\%933\&source=bl\&ots=g_TUGwm44h\&sig=ACfU3U31tuh2JVSjxrWFonpEBjfyQgEtig\&hl=zh-TW\&sa= X\&redir_esc $=y \& h l=z h-C N \&$ sourceid $=$ cndr\#v=onepage\&q=27.\%09Radebaugh $\% 2$ C \%20R.\%20Cryogenics. \%20MacMillan \%20 Encycl.\%20Chem.\%202002\%20\%20\%2C\%201\%E2\%80\%933\&f=false (accessed on 15 February 2021).

28. Ahluwalia, R.K.; Peng, J.-K.; Hua, T.Q. Cryo-compressed hydrogen storage. In Compendium of Hydrogen Energy; Gupta, R.B., Basile, A., Veziroğlu, T.N., Eds.; Woodhead Publishing: Sawston, UK, 2016; pp. 119-145.

29. Stetson, N.T.; McWhorter, S.; Ahn, C.C. Introduction to hydrogen storage. In Compendium of Hydrogen Energy; Gupta, R.B., Basile, A., Veziroğlu, T.N., Eds.; Woodhead Publishing: Sawston, UK, 2016; pp. 3-25.

30. Cirrone, D.; Makarov, D.; Molkov, V. Cryogenic hydrogen jets: Flammable envelope size and hazard distances for jet fire. ID191. In Proceedings of the International Conference on Hydrogen Safety, Adelaide, Australia, 24-26 September 2019.

31. NIST Chemistry WebBook, Thermophysical Properties of Fluid Systems. Available online: https://webbook.nist.gov/chemistry/ fluid/ (accessed on 15 April 2021).

32. Giannissi, S.G.; Venetsanos, A.G.; Cirrone, D.; Molkov, V.; Ren, Z.; Wen, J.; Friedrich, A.; Veser, A. Cold hydrogen blowdown release: An inter-comparison study. ID112. In Proceedings of the 9th International Conference on Hydrogen Safety, Edinburgh, UK, 21-23 September 2021.

33. Veser, A.; Friedrich, A.; Kuznetsov, M.; Jordan, T.; Kotchourko, N. Hydrogen blowdown release experiments at different temperatures in the discha-facility. In Proceedings of the 9th International Conference on Hydrogen Safety, Edinburgh, UK, 21-24 September 2021; pp. 442-454. 